\title{
A Comparison of the Phenotype of Dendritic Cells Derived from Discrete Peyer's Patch Macrophages of Non-Infected and Toxoplasma Gondii Infected Mice
}

\author{
Levi H. C. MAKALA ${ }^{1)}$, Julio C. S. REYES ${ }^{1,2)}$, Yoshifumi NISHIKAWA ${ }^{1)}$, Yoshinori TSUSHIMA ${ }^{1)}$, Xuenan XUAN ${ }^{1)}$, \\ Xiaohong HUANG ${ }^{1)}$ and Hideyuki NAGASAWA ${ }^{1) *}$ \\ ${ }^{1)}$ National Research Center for Protozoan Diseases, Obihiro University of Agriculture and Veterinary Medicine, Inada-Cho, Obihiro, \\ Hokkaido 080-8555, Japan and ${ }^{2)}$ Modulo de Produccion Bovina de Carne, Facultad de Ciencias Pecuarias, Universidad Tecnica del \\ Beni, Trinidad-Beni-Bolivia
}

(Received 31 October 2002/Accepted 29 January 2003)

ABSTRACT. A comparison of the expression of surface membrane antigens between dendritic cells (DC) derived from Peyer's patch macrophages (DPP-DC) of non-infected and Toxoplasma gondii (T. gondii) infected mice was performed. C57BL/6J mice aged 6-8 weeks of both sexes were infected orally with a $0.5 \mathrm{~m} l$ suspension containing $2 \times 10^{4}$ bradyzoites of the Beverley strain of $T$. gondii, sacrificed on day 8 and DC generated using discrete Peyer's patch macrophages (DPP-M $\varnothing$ ) as progenitor cells. When a comparison of the expression of surface membrane antigens between the antigen presenting cells (APC) obtained from discrete Peyer's patches of non-infected and $T$. gondii infected mice was carried out, no significant differences were observed in the macrophage progenitor and DC populations expression of F4/80, DEC-205, CD11c, CD80 (B7-1) and CD34. However, a significant decrease in MHC class II antigen levels and a down regulation of the co-stimulatory molecule CD86 (B7-2) were noted. B7-1 appeared to be the dominant co-stimulatory ligand, whereas B7-2, which was down regulated during $T$. gondii infection, had a weak expression. Taken together, these results may help clarify the role of DC in the complex network regulating surface membrane antigens, as well as, their capacity for antigen uptake, processing and presentation during toxoplasmosis.

KEY WORDS: dendritic cell, mouse, Peyer's patch macrophage, progenitor macrophage, Toxoplasma gondii.

J. Vet. Med. Sci. 65(5): 591-597, 2003

Dendritic cells (DC) represent a rare population of antigen presenting cells (APC) in the blood, non-lymphoid and lymphoid tissues. They play a key role in the onset of cellular immunity and many studies have shown that DC capture, process and present antigen to memory and naive $\mathrm{T}$ cells [24-27, 30]. The function of DC can be characterized by the dynamic regulation of differentiation/activation markers (CD83, CD25), of co-stimulatory molecules (CD40, CD80, CD86), and of class II major histocompatibility complexes (MHC class II) [14, 26-29, 31, 34].

The major mechanism by which immuno-competent hosts control Toxoplasma gondii (T. gondii) infection is considered to be cell-mediated immunity [12]. The microbicidal or micro-biostatic activity of activated APC [40] and non-phagocytic cells $[6,43]$ are the two major mechanisms of resistance to $T$. gondii infection. The physiologic regulation of Th phenotype development is still poorly understood, but because of the MHC class II restriction, attention has been focused on the major role of APC in the initiation of the immune response. In vitro studies have shown that activation of Th clones requires the presence of particular APC, i.e., DC or macrophages [8, 33].

High doses of the same soluble protein antigen given orally can result in non-responsiveness due to deletion or anergy of antigen-specific T cells [8], similar to what occurs following systemic administration of soluble proteins [33].

\footnotetext{
* Correspondence to: Prof. Nagasawa, H., National Research Center for Protozoan Diseases, Obihiro University of Agriculture and Veterinary Medicine, Inada-cho, Obihiro, Hokkaido 0808555 , Japan.
}

However, not all oral encounters with antigen result in tolerance. Local and systemic $\mathrm{T}$ cell priming can occur when soluble antigens are administered with an ADP-ribosylating adjuvant, such as cholera toxin, which results in a Th2-dominant response, or following infection with a mucosal pathogen, such as Salmonella typhimurium or T. gondii, which results in a Th1-dominant response. Despite recent progress, the mechanisms by which such disparate $\mathrm{T}$ cell immune responses occur following the administration of orally administered antigens are still poorly understood. To address this issue, we have focused our studies on the phenotype and function DC derived from discrete Peyer's patch macrophages (DPP-DC), because Peyer's patches (PP) are the primary sites for the induction of immune responses in the intestinal mucosa and are representative of lymphoid follicles present in diffuse mucosal tissues.

It has been postulated that the DC system consists of distinct cellular subsets, which may arise from either a myeloid or lymphoid precursor [38]. In the mouse, these two types of DCs have been shown to express either high levels of CD11b (myeloid) or CD8 (lymphoid) molecules, respectively. In addition, Iwasaki and Kelsall [17] recently described a third subset of DC that does not express either of these markers (double-negative (DN) DC) [16].

The aim of this study was to compare the phenotype of DPP-DC of non-infected and $T$. gondii infected mice to better understand the dynamic regulation of APC specific antigens during Toxoplasmosis. We characterized the phenotype of DPP-DC from both $T$. gondii infected and non-infected mice. Our results, showed a significant 
decrease in MHC class II antigen levels and a down regulation of the co-stimulatory molecule CD86 (B7-2), making B7-1 appear to be the dominant co-stimulatory ligand during Toxoplasmosis.

\section{MATERIALS AND METHODS}

Animals: Discrete Peyer's patches (DPP) were obtained from 6-8 week aged C57BL/6J mice and both sexes were used. Mice were kept at room temperature with a 12:12 hr light-dark cycle and housed in cages in groups of 5 mice/ cage with free access to sterilized tap water and a standard commercial diet (Ca-1, CLEA Inc. Japan).

Parasites: The low virulent Beverly strain of $T$. gondii was maintained in our laboratory by intraperitoneal (i.p.) passage of brain cysts into ICR mice. Brains were removed from $T$. gondii infected mice 6 months after infection and were homogenized in RPMI-1640 medium (Sigma-Aldrich, UK). To obtain bradyzoites, brain homogenates were resuspended in $50 \mathrm{~m} l$ of of RPMI-1640, the cysts were purified from brain using $25 \%$ gum Arabic $\left(\right.$ Sigma $\left.^{\circledR}\right)$. Briefly, 2 $\mathrm{m} l$ of the gum Arabic of $1.07 \mathrm{sg}$ (specific gravity) were added to each glass tube and $2 \mathrm{~m} l$ of the gum Arabic of 1.05 sg were dispensed slowly to the each tube. After $10 \mathrm{~min}$ of centrifugation at $2,100 \times \mathrm{g}$ at $15^{\circ} \mathrm{C}$, the pellets collected from all tubes were treated with $10 \mathrm{ml}$ of $0.25 \%$ trypsin at $37^{\circ} \mathrm{C}$ for $10 \mathrm{~min}$. The bradyzoite suspension was filtered through gauze and washed twice with $40-50 \mathrm{ml}$ of RPMI1640 by centrifugation at $2,100 \times \mathrm{g}$ at $4^{\circ} \mathrm{C}$ for $15 \mathrm{~min}$. The pellets of the last washing were re-suspended in $5 \mathrm{ml}$ of RPMI-1640 containing 10\% FCS. The number of bradyzoites was estimated using a haemotocytometer and adjusted to $2 \times 10^{4}$ of bradyzoites $/ \mathrm{m} l$.

Infection: C57BL/6J mice were infected orally with 0.5 $\mathrm{m} l$ of suspension containing $2 \times 10^{4}$ bradyzoites of Beverley strain of $T$. gondii and sacrificed on day 8 . The day of infection was referred to as day 0 .

Tissue culture media. Except where stated, all cell manipulations were carried out at room temperature. Tissue culture medium was Minimum Essential Medium Eagle-MEM, $\left(\right.$ Sigma ${ }^{\circledR}$, poole, Dorset, UK) supplemented with $8 \%$ FBS and $50 \mathrm{mg}$ of Kanamycin.

Cytokines: The following cytokines were used in this study: murine recombinant granulocyte-monocyte colonystimulator factor (GM-CSF) (Sigma) and murine recombinant IL-4 (Sigma).

Monoclonal antibodies: The following labelled antimouse monoclonal antibodies specific for antigen presenting cells used were: anti-CD11c PE (HL3) [35]; anti-DEC205 FITC (NLDC-145) [18, 23]; anti-MHC class II (I-A $\left.{ }^{\mathrm{b}}\right)$ FITC (AF6-120.1) [38]; anti-CD80 FITC (B7-1) [37]; antiCD86 FITC (B7-2) [13]; anti-CD11b (Mac-1) FITC (M1/ 70) [32] (Pharmingen International, U.S.A.); anti-CD34 FITC (MEC 14.7) [10]: and anti-F4/80 FITC (C1:A3-1) [1] (Serotec Ltd., Oxford, U.K.). The anti-MHC class II (antimouse $I-A^{b}\left(A_{\alpha}^{b}\right)(A F 6-120.1)$ used in this study reacts with the $\alpha$ chain of the I-A ${ }^{b}$ MHC class II allo-antigen, and cross reacts with cells from mice of the $\mathrm{H}-2^{\mathrm{K}}, \mathrm{H}-2^{\mathrm{p}}$ and $\mathrm{H}-2^{\mathrm{u}}$ haplotypes which cover the mice types used in our study. All experiments using animals were carried out in accordance with rules and ordinances of the National Research Center for Protozoan Diseases, Obihiro University of Agriculture and Veterinary Medicine, and are in line with acceptable international standards.

Macrophage and dendritic cell generation: Single cells suspensions from DPP of mice were obtained using a modification of previously described methods [24, 26-30]. Immediately after slaughter, the skin covering the abdomen was removed. The DPP were identified by eye and carefully dissected out using scissors and washed two times in $25 \mathrm{ml}$ of fresh culture median. Peyer's patches were mechanically disrupted using a $5 \mathrm{~m} l$ syringe head and $70 \mu \mathrm{m}$ nylon cell strainer (Becton, Dickinson, NJ, U.S.A.) in culture media. The resultant cell population, were then filtered twice using a $70 \mu \mathrm{m}$ nylon cell strainer. The resulting cells were re-suspended in $8 \mathrm{~m} l$ of tissue culture medium in a glass centrifuge tube and layered unto $2 \mathrm{~m} l$ of $14.5 \%$ weight by volume (w/ v) metrizamide (Nycomed AS, Olso, Norway) in RPMI 1640 without bicarbonate, supplemented with $2 \%$ normal mouse serum (NMS). The suspension was centrifuged at $400 \mathrm{~g}$ for $30 \mathrm{~min}$ at $4^{\circ} \mathrm{C}$ and low-density cells (LDC) removed from the interface. These were resident discrete Peyer's patch dendritic cells (Res-DC) and their purity as determined by the dendritic cell marker DEC-205 was always greater than $90 \%$. The remaining pellet was re-suspended in tissue culture medium and filtered though a nylon cell strainer. The suspension was centrifuge at $400 \mathrm{~g}$ for 5 min at $4^{\circ} \mathrm{C}$ and re-suspended in $10 \mathrm{~m} l$ of fresh culture medium. Macrophages were obtained following an overnight adherent-step in tissue culture medium. The purity of the DPP macrophage as determined by flow cytometry, using the macrophage specific marker anti-mouse F4/80 was always greater than $90 \%$. Unless otherwise stated all operation were carried on ice. In three different experiments, the adherent cells were cultured in 4-6 $\mathrm{ml}$ culture medium with or without growth factors $(1,000 \mathrm{U} / \mathrm{ml} \mathrm{GM}$ $\mathrm{CSF}$ and 1,000 U/m $l \mathrm{IL}-4)$ for 7 days. Non-adherent cells and loosely adherent cells were harvested by moderately vigorous aspiration. These were referred to as the DPP-DC. The purity of DPP-DC as determined by flow cytometry using the DC specific marker DEC-205 was always greater than $90 \%$.

Light and electron microscopy: For light microscopy slide cell preparations were air-dried, fixed and stained using Giemsa's stain. Cells were observed under a light microscope and the proportion of cells showing morphological features of DC were identified using the following criteria: relative size; cytoplasm;nucleus ratio; shape and position of the nucleus; vacuolation of the cytoplasm and cytoplasmic protuberances. Discrete Peyer's patch macrophages (DPP-M $\phi)$ were used as controls. For electron microscopy cells were pelleted and fixed overnight at $4^{\circ} \mathrm{C}$ in $2.5 \%$ glutaraldehyde in $0.1 \mathrm{M}$ cacodylate buffer for $1 \mathrm{hr}$, rinsed in buffer, post-fixed in $2 \%$ osmium tetroxide in $0.2 \mathrm{M}$ 
cacodylate buffer for $1 \mathrm{hr}$, dehydrated through a graded ethanol series and finally embeded in TAAB Epon 812 low viscosity resin. Ultrathin sections $(70 \mathrm{~nm})$ were cut using a diamond knife, grid stained with $1 \%$ uranyl acetate and lead citrate and analyzed by a Hitachi transmission electron microscope (Hitachi, Ltd., Tokyo, Japan).

Flow cytometry: Surface antigen expression of CD11c, DEC-205, CD34, MHC class II antigens, CD80, CD86, CD11b (Mac-1) and F4/80 was measured on cytokine treated and untreated samples by flow cytometry. $2 \times 10^{5}$ cells/sample were washed once in PBS containing 5\% FBS and $0.02 \% \mathrm{NaN}_{3}$ for $1 \mathrm{~min}$ at $400 \mathrm{~g}$. Binding was visualized with a single step technique involving incubation with $5 \mu \mathrm{l}$ of the following labeled anti-mouse $\mathrm{mAb}$ anti-CD11c PE (HL3); anti-DEC-205 FITC (NLDC-145); anti-MHC class

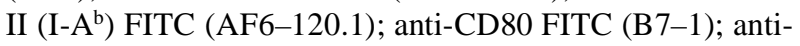
CD86 FITC (B7-2); anti-CD11b (Mac-1) FITC (M1/70) (Pharmingen International, U.S.A.); anti-CD34 FITC (MEC 14.7): and anti-F4/80 FITC (C1:A3-1) (Serotec Ltd., Oxford, U.K.). After incubation cells were washed, analyzed and fluorescence quantified using a Coulter EPICSXL flow cytometer at $488 \mathrm{~nm}$. Cells were electronically gated on forward angle light scatter to exclude debri and on $90^{\circ}$ light scatter to exclude granulocytes.

\section{RESULTS}

Yield, purity and viability of the generated dendritic cells: The average yield of cell populations from DPP of 20 mice isolated using mechanical disruption before metrizamide gradients was approximately of $3.8 \times 10^{8}$ in non-infected mice and $2.7 \times 10^{8}$ in infected mice. After metrizamide density gradient centrifugation the cell suspension consisted approximately $2.4 \times 10^{8}$ in non-infected mice and $3.1 \times 10^{8}$ in infected mice, about 1.5 times more in infected mice compared to non-infected mice. After incubation for seven days with GF recovery was approximately $3.5 \times 10^{6}$ in noninfected mice and $8.5 \times 10^{6}$ in infected mice, double or more of the initial amount incubated with growth factors in noninfected mice. In some experiments the number of adherent cells following overnight culture was determined (Table 1). In non-infected mice this number was approximately $1.4 \times$ $10^{6}$ while infected mice consisted of approximately $6.3 \times$ $10^{6}$, exhibiting a four-fold increase. Viability of the recovered cells as determined by trypan blue exclusion was always greater than $90 \%$.
Morphology of the generated dendritic cells: DPP-DC, were characterized by morphology under light microscopy and discrete Peyer's patch macrophages were used as controls. As identified microscopically, a non-adherent cell population could be observed. Subjectively, DC from both T. gondii infected and non-infected mice, were generally smaller than Peyer's patch macrophages and these cells showed evidence of cytoplasmic protuberance or dendrites and in some cases cells appeared to take up apoptotic bodies by phagocytosis and receptor mediated mechanisms (Fig. 1). Both cells from $T$. gondii infected and non-infected mice were observed under light microscope continually extending, retracting and reoriented their cellular processes in live culture when observed over a longer period of time (data not shown). Ultrastructural investigations by electron microscopy showed further evidence of typical DC characteristics, such as the above-mentioned cytoplasmic veils (V), irregularly shaped excentric nuclei $(\mathrm{N})$, multi-vesicular bodies (MVB) and autophagosomes (AP) (data not shown). It can be seen in Fig. 1 that, there were no changes observed in the morphology of the progenitor discrete Peyer's patch macrophages, nor the dendritic cells derived from discrete Peyer's patch dendritic cells.

Phenotypic analysis of discrete Peyer's patch cells in infected mice: Discrete Peyer's patch cells were also examined for expression of specific DC surface membrane antigens in Toxoplasma gondii infected mice and a comparison with DC from discrete Peyer's patch macrophages of noninfected mice was made. Expression of MHC-class II antigens in the original population of both infected and noninfected mice was not significantly different as shown by the phenotypic profiles (Fig. 2). However, the expression of MHC-class II molecules in cells incubated for 7 days in the presence of growth factor in infected mice was significantly down regulated compared to cells incubated for 7 days in the presence of growth factor in non-infected mice (Fig. 2). A similar trend was observed in the expression of the co-stimulatory molecule CD86 (B7-2). Incubation for 7 days in the presence of growth factor significantly down regulated CD86 (B7-2) expression in non-infected mice compared to infected mice (Fig. 3). Thus, the co-stimulatory molecules B7-1 and B7-2 were differentially expressed on the generated DC. A high level of B7-1 and B7-2 was expressed on DC derived from discrete Peyer's patches of non-infected mice, whereas a lower level of B7-2 was expressed in DC from infected mice.

Table 1. Number of cells isolated from discrete Peyer's patches of Toxoplasma gondii infected and non-infected mice $( \pm \mathrm{SD})$

\begin{tabular}{lcccc}
\hline Mice & $\begin{array}{c}\text { Before } \\
\text { Metrizamide } \\
\text { Gradient }\end{array}$ & $\begin{array}{c}\text { After } \\
\text { Metrizamide } \\
\text { Gradient }\end{array}$ & $\begin{array}{c}\text { After Overnight } \\
\text { Incubation }\end{array}$ & $\begin{array}{c}\text { After 7 days } \\
\text { Incubation } \\
\text { with Growth } \\
\text { factors }\end{array}$ \\
\hline $\begin{array}{l}\text { Non-infected } \\
\text { Infected }\end{array}$ & $(3.8 \pm 0.2) \times 10^{8}$ & $(2.4 \pm 0.1) \times 10^{8}$ & $(1.4 \pm 0.1) \times 10^{6}$ & $(3.5 \pm 1.1) \times 10^{6}$ \\
\hline
\end{tabular}




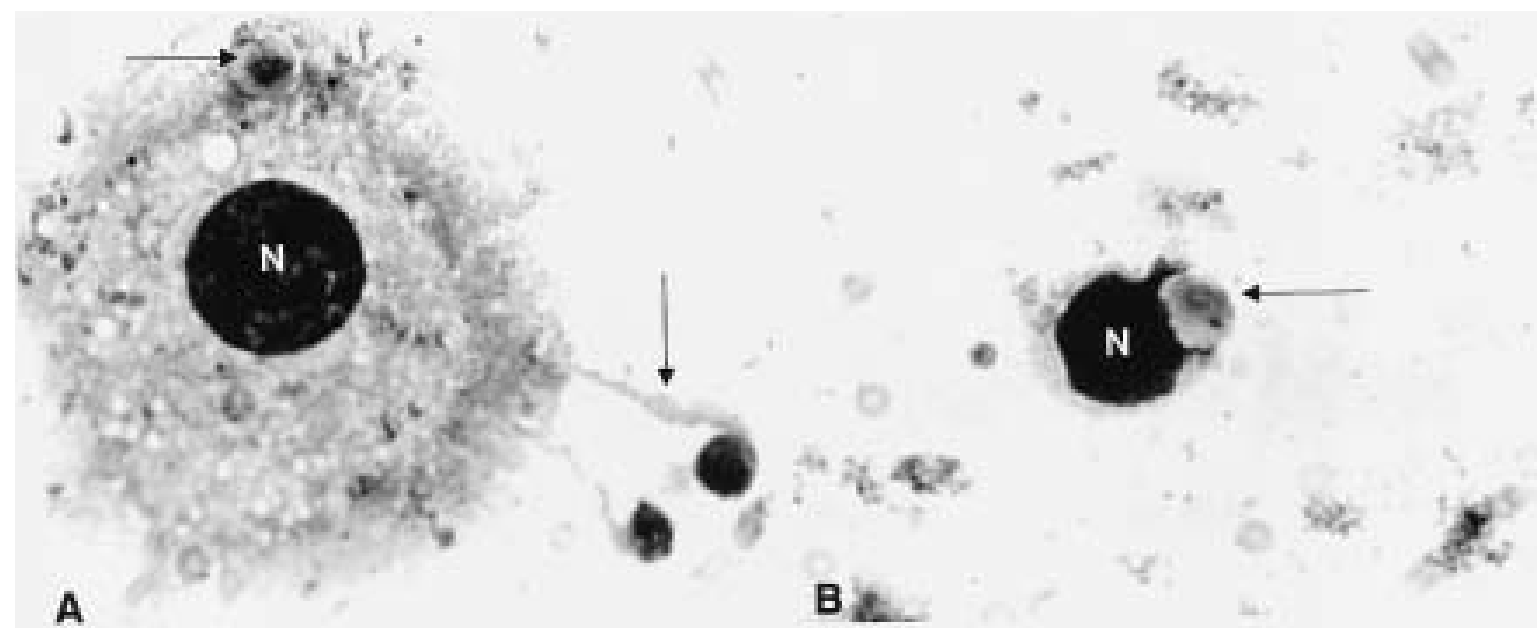

Fig. 1. Giemsa-stained light microscopic visualization of: (A) a discrete Peyer's patch progenitor macrophage engulfing apoptotic bodies by phagocytosis (see arrows) (B) a generated Peyer's patch macrophage-derived dendritic cells (DC) engulfing an apoptotic body by a receptor mediated mechanism (see arrow) $(\times 870)$.

\section{DISCUSSION}

We have isolated a CD1 $1^{\text {low }}\left(\mathrm{CD} 11 \mathrm{c}^{-\mathrm{ve}}\right)$, MHC class II ${ }^{\text {low }}$, $\mathrm{CD}^{\text {low }}\left(\mathrm{B} 7-2^{\text {low }}\right)$ DPP-DC population from $T$. gondii infected $\mathrm{C} 57 \mathrm{BL} / 6 \mathrm{~J}$ mice. The precise role of dendritic cell (DC) [39] populations in regulating the immune responses to orally administered antigens remains unclear. We have focused our studies on the phenotype of DC derived from discrete Peyer's patch macrophages, as this lymphoid tissue is the primary site for the induction of mucosal immune responses, such as the differentiation of B cells capable of producing secretory IgA. It is also likely the initial site for the generation of regulatory $\mathrm{T}$ cells producing IL-10 and TGF- $\beta$ after low dose antigen feeding. In addition, prior studies suggested that dendritic cells derived from Peyer's patch macrophages may be unique in their ability to prime $\mathrm{T}$ cells for providing help for IgA B cell differentiation [39]. However, not all oral encounters with antigens result in tolerance. Local and systemic priming can occur following infection with a mucosal pathogen such as $T$. gondii $[15$, 39].

The freshly isolated DPP macrophage population showed a high expression of the macrophage marker F4/80, CD34 (data not shown) a marker typical of haemopoietic progenitors [10], high MHC class II expression and a very low expression of CD11c. The expression of CD34 indicates that our generated cells have a haemopoietic rather than a myeloid origin. The generated DPP macrophage derived dendritic cells exhibited very low or virtually no CD11c expression. CD11c- DC, have been described in the blood [42]. Two peripheral blood DC subsets have been described and are distinguished based on their ability or inability to express CD11c [41]. The CD11c- DC, have been recently reported to express high levels of CD123 [interleukin (IL)3R $\alpha$ ] [36]. Moreover, functional differences between CD11 $\mathrm{c}^{+}$and CD11c- DC have been described [35, 41].
CD11 $\mathrm{c}^{+} \mathrm{DC}$ are more potent in T cell-stimulating activity, express CD45RO, and have higher levels of MHC class II and adhesion molecules $[35,41]$. In other studies, CD11cDC, have been shown to have a low MHC class II expression and down regulated co-stimulatory molecules expression in contrast to CD $11 \mathrm{c}^{+}$DC [42]. However, the expression of MHC-class II molecules in cells incubated for 7 days in the presence of growth factor in infected mice was significantly down regulated compared to cells incubated for 7 days in the presence of growth factor in non-infected mice (Fig. 2). A similar trend was observed in the expression of the co-stimulatory molecule CD86 (B7-2) incubation for 7 days in the presence of growth factor significantly down regulated CD86 (B7-2) expression in non-infected mice compared to infected mice (Fig. 3). The up-regulation of MHC class II and co-stimulatory molecules in CD11 $\mathrm{c}^{+}$ DC after activation is in agreement with published literature because these signals are widely discussed as a measure of DC activation/maturation [14]. B7-1 and B7-2 when upregulated binds to $\mathrm{T}$ cell surface molecules $\mathrm{CD} 28$ and CTLA-4, which may be critical in prolonging the primary $\mathrm{T}$ cell response or co-stimulating the secondary $\mathrm{T}$ cell responses [2,31]. It has been suggested that the presence of B7-1 favours the activation of Th1 lymphocytes whereas B7-2 favours the priming of Th2 cells [7, 20]. From this viewpoint, DC may therefore, play an important role not only in the initiation of adaptive immunity to $T$. gondii but also in the early induction of innate immunity to the parasite.

In the present study, C57BL/6J mice were infected orally with $0.5 \mathrm{~m} l$ of suspension containing $2 \times 10^{4}$ bradyzoites of Beverley strain of $T$. gondii. The bradyzoites survive within cysts and are effectively isolated from the host immune system by the cyst wall, which is composed mainly of host tissue-derived products. The ability of bradyzoites to escape the host immune response and persist in a quiescent form 

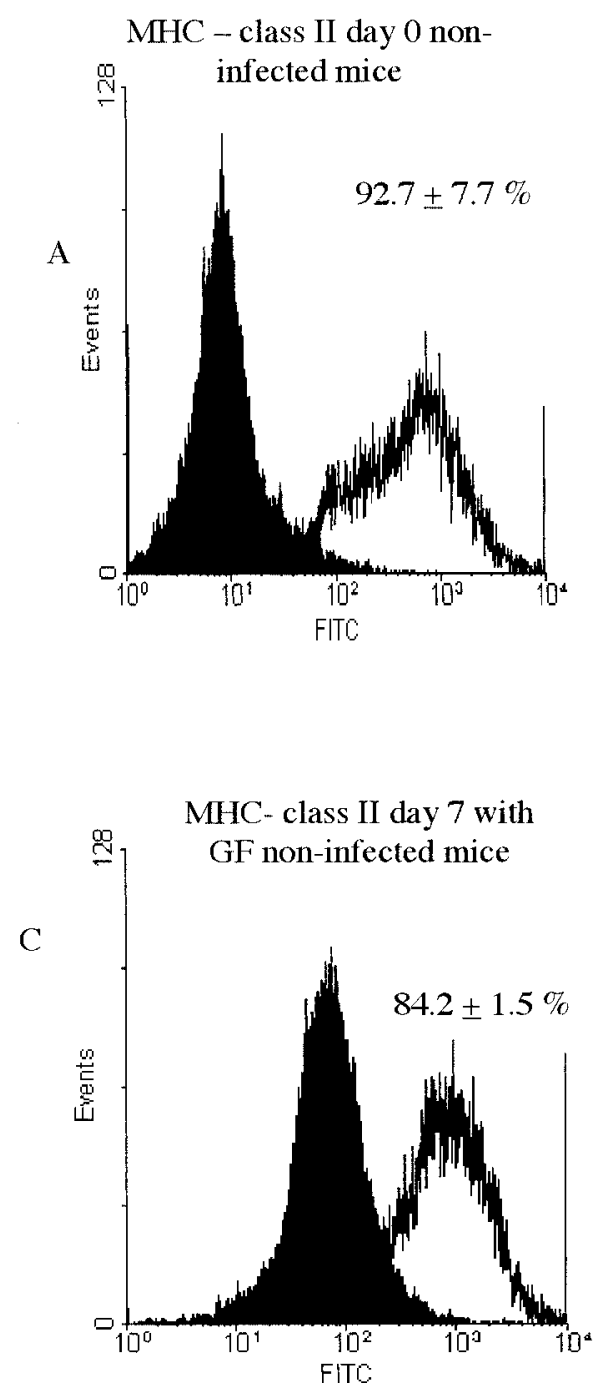

MHC-class II day 0 infected mice

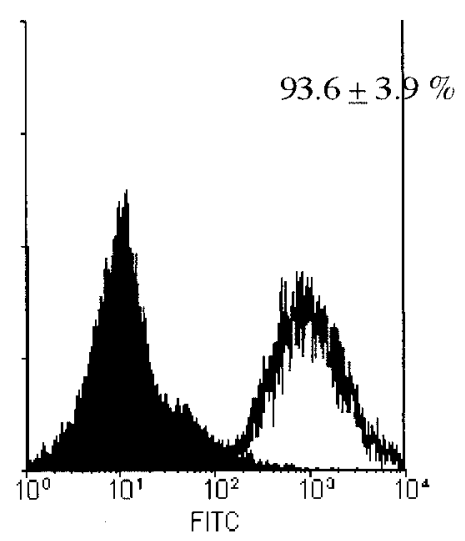

MHC- class II day 7 with GF infected mice

$\mathrm{D}$

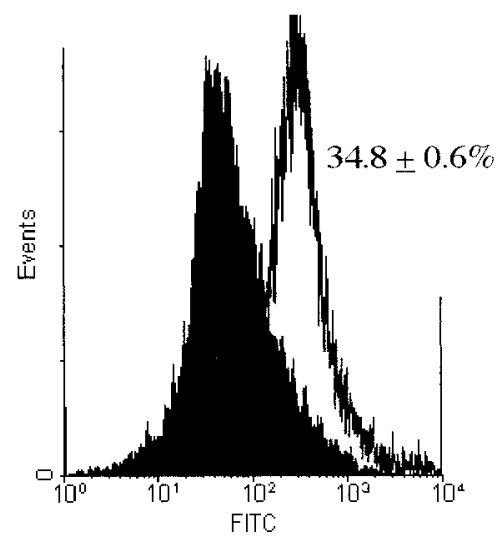

Fig. 2. One parameter histograms showing expression of MHC class II (AF6-120.1) in: (A) Discrete Peyer's patch (DPP) cells from non-infected mice at day 0; (B) DPP cells from infected mice at day 0; (C) DPP cells from non-infected mice following 7 days of culture with GM-CSF + IL-4; (D) DPP cell from infected mice following 7 days of culture with GM-CSF + IL-4. Percentages of positive cells are given in each panel. The Y axis represents frequencies showing numbers of positive cells and the $\mathrm{X}$-axis is the log intensity of green fluorescence. Data are representative of three experiments and show the respective control staining (filled histograms) and specific monoclonal antibody binding (open histograms) \pm SD.

within the host is therefore another key event in the T. gondii life cycle. The bradyzoites are infective for either definitive or intermediate hosts and are largely responsible for parasite transmission to different species of mammals and birds [22]. The susceptibility of different mouse strains to infection with $T$. gondii varies dramatically depending on the route of infection and the mouse $\mathrm{H}-2$ haplotype [2-4]. Mouse strains that are susceptible to oral infection (such as strain C57BL/ $6)$, unlike those that are resistant via this route of infection, have been shown to develop severe necrotic lesions in their small intestines $[11,12]$. The mucosal epithelial layer provides the interface between the external and the internal environments of the gastrointestinal tract. The intestineassociated lymphoid tissue serves as an immunological barrier against a wide range of infectious agents, including orally acquired parasites such as $T$. gondii [21].

Our results indicate that DC derived from both discrete Peyer's patches of infected and non-infected mice expressed MHC class II and co-stimulatory molecules and thus could be able to present an antigen and sensitize $\mathrm{T}$ cells in vivo. Our results also suggest that the presence of infectious microorganisms may have a profound impact on the DC system in vivo, thus leaving many questions regarding the overall role of DC in the initiation of the immune response 


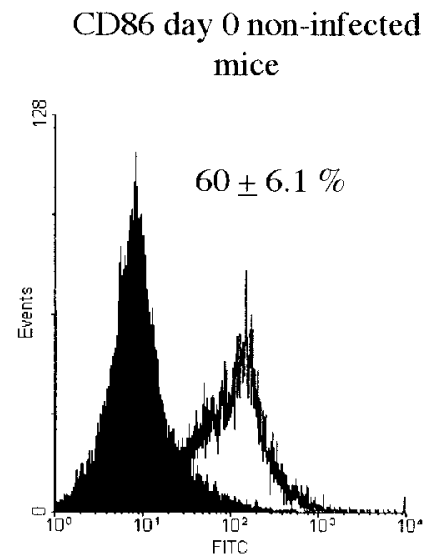

A

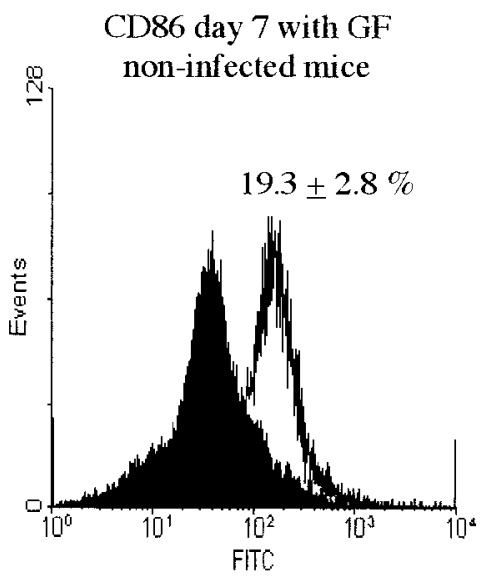

B

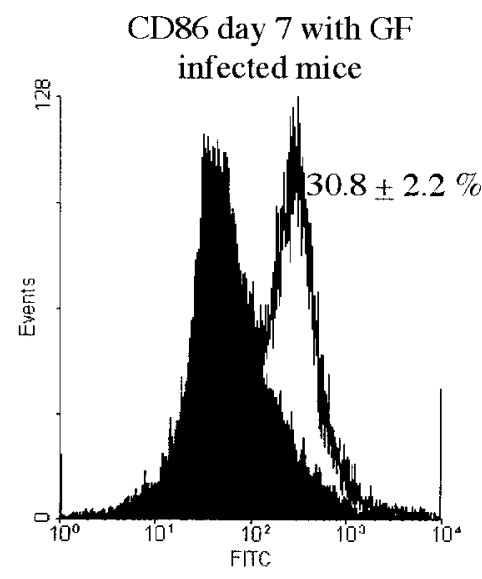

$\mathrm{C}$

Fig. 3. One parameter histograms showing expression of CD80 (B7-2)(GL1) in: (A) Discrete Peyer's patch (DPP) cells from non infected mice at day 0; (B) DPP cells from non-infected mice at day 7 of culture with GM-CSF + IL-4; (C) DPP cells from infected mice following 7 days of culture with GM-CSF + IL-4. Percentages of positive cells are given in each panel. The Y axis represents frequencies showing numbers of positive cells and the $\mathrm{X}$-axis is the log intensity of green fluorescence. Data are representative of three experiments and show the respective control staining (filled histograms) and specific monoclonal antibody binding (open histograms) \pm SD .

[19]. During natural peroral infection this process is initiated locally in intestinal tissue [9]. Are DC or macrophages (in the Peyer's patches and/or lamina propria) themselves infected or do they acquire antigens shed by the parasite into the extra-cellular milieu? What is the nature of the parasite molecules responsible for DC activation? Do molecules act directly on DC through cell surface receptors or indirectly through the induction of inflammatory cytokines? What regulates the expression of membrane surface antigens? Answers to these questions should not only lead to a better understanding of immune responses to intracellular parasites but, also may yield general strategies for stimulating host resistance through its innate and acquired immunologic components.

ACKNOWLEDGEMENTS. We are indebted to the Japanese Society for the Promotion of Science (JSPS) for financial support. The first author was supported by a JSPS research fellowship for young scientists. This study was also supported by Grants-in-Aid for scientific Research from the Ministry of Education, Culture, Sports, Science and Technology of Japan.

\section{REFERENCES}

1. Austyn, J. M. and Gordon, S. 1981. F4/80, a monoclonal antibody directed specifically against the mouse macrophage. Eur. J. Immunol. 11: 805-815.

2. Bluestone, J. A. 1995. New perspectives of CD28-B7-mediated T cell co-stimulation. Immunity 2: 555-559.

3. Bourguin, I., Moser, M., Buzoni-Gatel, D., Tielemans, F., Bout, D., Urbain, J. and Leo, O. 1998. Murine dendritic cells pulsed in vitro with Toxoplasma gondii antigens induce protective immunity in vivo. Infect. Immun. 66: 4867-4874.
4. Buxton, D. 1993. Toxoplasmosis: the first commercial vaccine. Parasitol. Today 9: 335-337.

5. Dimier, I. H. and Bout, D.T. 1993a. Co-operation of interleukin-1 beta and tumour necrosis factor-alpha in the activation of human umbilical vein endothelial cells to inhibit Toxoplasma gondii replication. Immunology 79: 336-338.

6. Dimier, I. H. and Bout, D.T. 1993b. Rat intestinal epithelial cell line IEC-6 is activated by recombinant interferon-gamma to inhibit replication of the coccidian Toxoplasma gondii. Eur. J. Immunol. 23: 981-983.

7. Freeman, G. J., Boussiotis, V. A., Anumanthan, A., Bernstein, G. M., Ke, X. Y., Rennert, P. D., Gray, G. S., Gribben, J. G. and Nadler, L. M. 1995. B7-1 and B7-2 do not deliver identical costimulatory signals, since B7-2 but not B7-1 preferentially co-stimulates the initial production of IL-4. Immunity $\mathbf{2}$ : 523-532.

8. Friedman, A. and Weiner, H. L. 1994. Induction of anergy or active suppression following oral tolerance is determined by antigen dosage. Proc. Natl. Acad. Sci. U.S.A. 91: 6688-6692.

9. Frenkel, J. K. 1990. Toxoplasmosis in human beings. J. Am Vet. Med. Assoc. 196: 240-248.

10. Garlanda, C., Berthier, R., Garin, J., Stoppacciaro, A., Ruco, L., Vittet, D., Gulino, D., Matteucci, C., Mantovani, A., Vecchi, A. and Dejana, E. 1997. Characterization of MEC 14.7, a new monoclonal antibody recognizing mouse CD34: a useful reage for identifying and characterizing blood vessels and hematopoietic precursors. Eur. J. Cell. Biol. 73: 368-377.

11. Gazzinelli, R. T., Denkers, E. Y. and Sher, A. 1993. Host resistance to Toxoplasma gondii: model for studying the selective induction of cell-mediated immunity by intracellular parasites. Infect. Agents Dis. 2: 139-149.

12. Gazzinelli, R. T., Hakim, F. T., Hieny, S., Shearer, G. M. and Sher, A. 1991. Synergistic role of CD4+ and CD8+ T lymphocytes in IFN- production and protective immunity induced by an attenuated Toxoplasma gondii vaccine. J. Immunol. 146: 286-292. 
13. Hakamada-Taguchi, R., Kato, T., Ushijima, H., Murakami, M., Uede, T. and Nariuchi, H. 1998. Expression and co-stimulatory function of B7-2 on murine CD4+ T cells. Eur. J. Immunol. 28: $865-873$.

14. Hart D. N. 1997. Dendritic cells: unique leukocyte populations, which control the primary immune response. Blood 90: 32453287.

15. Iwasaki, A. and Kelsall, B. L. 1999. Freshly isolated Peyer's patch, but not spleen, dendritic cells produce interleukin 10 and induce the differentiation of T helper type 2 cells. J. Exp. Med. 190: $229-240$.

16. Iwasaki, A. and Kelsall, B. L. 2000. Localization of distinct Peyer's patch dendritic cell subsets and their recruitment by chemokines macrophage inflammatory protein (MIP)-3, MIP3, and secondary lymphoid organ chemokine. J. Exp. Med. 191: $1381-1394$.

17. Iwasaki, A. and Kelsall, B. L. 2001. Unique functions of $\mathrm{CD} 11 \mathrm{~b}+, \mathrm{CD} 8 \alpha+$. And double-negative Peyer's patch dendritic cells. J. Immunol. 166: 4884-4890.

18. Jiang, W., Swinggard, W. J., Heufler, C., Peng, M., Mirza, A., Steinman, R. M. and Nussenzweig, M. C. 1995. The receptor DEC-205 expressed by dendritic cells and thymic epithelial cells is involved in antigen processing. Nature (Lond.) 375 : 151-155.

19. Johnson, L. L. and Sayles, P. C. 1997. Interleukin-12, dendritic cells, and the initiation of host-protective mechanisms against Toxoplasma gondii. J. Exp. Med. 186: 1799-1802.

20. Kuchroo, V. K., Das, M. P., Brown, J. A., Ranger, A. M., Zamvil, S. S., Sobel, R. A., Weiner, H. L., Nabavi, N. and Glimcher, L. H. 1995. B7-1 and B7-2 costimulatory molecules activate differentially the Th1/Th2 developmental pathways: application to autoimmune disease therapy. Cell 80: 707-718.

21. Lefrancois, L., B. Fuller, J. W., Huleatt, S., Olson, L. and Puddington. 1997. On the front lines: intraepithelial lymphocytes as primary effectors of intestinal immunity. Springer Semin. Immunopathol. 18: 463-475.

22. Luft, B. J., Brooks, R. G., Conley, F. K., McCabe, R. E. and Remington, J. S. 1984. Toxoplasmic encephalitis in patients with acquired immune response deficiency syndrome. JAMA. 252: 913-917.

23. Maeda, K., Burton, G. F., Padgett, D. A., Conrad, D. H., Huff, T. F., Masuda, A., Szakal, A. K. and Tew, J. G. 1992. Murine follicular dendritic cells and low affinity Fc receptors for IgE (Fc epsilon RII). J. Immunol. 148: 2340-2347.

24. Makala, L. H. C. 1996. Isolation and Characterization of Pig Peyer's Patch Dendritic Cell. Ph. D. Thesis. University of Bristol, Bristol, England, UK.

25. Makala, L. H. C., Haverson, K., Stokes, C. R., Bailey, M. and Bland, P. W. 1998. Isolation and characterization of pig Peyer's patch dendritic cell. Vet. Immunol. Immunnopathol. 61: 67-81.

26. Makala, L. H. C., Suzuki, N. and Nagasawa, H. 2002a. Peyer's patch: Organized lymphoid structure for the induction of mucosal immune responses in the intestine. Pathobiology (in press)

27. Makala, L. H. C. and Nagasawa, H. 2002b. Dendritic cells: A specialized complex system of antigen presenting cell. J. Vet. Med. Sci. 64: 181-193.

28. Makala, L. H. C., Nishikawa, Y., Kamada, T., Suzuki, H., Xuan, X., Igarashi, I. and Nagasawa, H. 2001b. Comparison of the accessory activity of murine peritoneal cavity macrophage derived dendritic cells and peritoneal cavity macrophage in a mixed lymphocyte reaction. J. Vet. Med. Sci. 63: 1271-1277.

29. Makala, L. H. C., Nishikawa, Y., Kamada, T., Xuan, X. and Nagasawa, H. 2001c. Antigen presentation by murine peritoneal cavity macrophage-derived dendritic cells. Pathobiology 69: $104-112$

30. Makala, L. H. C., Nishikawa, Y., Mishima, M., Xuan, X., Suzuki, N., Fujisaki, K., Mikami, T. and Nagasawa, H. 2002c. Phenotype \& function of murine peritoneal cavity macrophage derived-dendritic cell. J. Vet. Med. Sci. 64: 813-820.

31. McLellan, A. D., Starling, G. C., Williams, L. A., Hock, B. D. and Hart, D. N. 1995. Activation of human peripheral blood dendritic cells induces the CD86 co-stimulatory molecule. Eur. J. Immunol. 25: 2064-2068.

32. Metlay, J. B., Witmer-pack, M. D., Agger, R., Crowley, M. T., Lawless, D. and Steinman, M. R. 1990. The distinct leukocyte integrins of mouse spleen dendritic cell as identified with new hamster monoclonal antibodies. J. Exp. Med. 171: 1753-1771.

33. Mondino, A., A. Khoruts and Jenkins, M. K. 1996. The anatomy of T-cell activation and tolerance. Proc. Natl. Acad. Sci. U.S.A. 93: 2245-2252.

34. Nijman, H. W., Kleijmeer, M. J., Ossevoort, M. A., Oorschot, V. M., Vierboom, M. P., van de Keur, M., Kenemans, P., Kast, W. M., Geuze, H. J. and Melief, C. J. 1995. Antigen capture and major histocompatibility class II compartments of freshly isolated and cultured human blood dendritic cells. J. Exp. Med. 182: $163-174$.

35. O'Doherty, U., Peng, M., Gezelter, S., Swiggard, W.J., Betjes, M., Bhardwaj, N. and Steinman, R. M. 1994. Human blood contains two subsets of dendritic cells, one immunologically mature and the other immature. Immunology 82: 487-493.

36. Olweus, J., BitMansour, A., Warnke, R., Thompson, P. A., Carballido, J., Picker, L. J. and Lund-Johansen, F. 1997. Dendritic cell ontogeny: a human dendritic cell lineage of myeloid origin. Proc. Natl. Acad. Sci. U.S.A. 94: 12551-12556.

37. Razi-Wolf, Z., Freeman, G.J., Galvin, F., Benacerra, B., Nadler, L. and Reiser, H. 1992. Expression and function of the murine B7 antigen, the major costimulatory molecules expressed by peritoneal exudates cells. Proc. Natl. Acad. Sci. U.S.A. 89: $4210-4214$.

38. Shortman, K. and Caux, C. 1997. Dendritic cell development: multiple pathways to nature's adjuvants. Stem Cells 15: 409419.

39. Spalding, D. M. and Griffin, J. A. 1986. Different pathways of differentiation of pre-B cell lines are induced by dendritic cells and $\mathrm{T}$ cells from different lymphoid tissues. Cell 44: 507-515.

40. Suzuki, Y., Orellana, M.A., Schreiber, R.D. and Remington, J.S. 1988. Interferon-gamma: the major mediator of resistance against Toxoplasma gondii. Science 240: 516-518.

41. Thomas, R. and Lipsky, P. E. 1994. Human peripheral blood dendritic cell subsets. Isolation and characterization of precursor and mature antigen-presenting cells. J. Immunol. 153: 4016-4028.

42. Willmann, K. and Dunne, J. F. 2000. A flow cytometric immune function assay for human peripheral blood dendritic cells. J. Leukoc. Biol. 67: 536-544.

43. Woodman, J. P., Dimier, I. H. and Bout, D. T. 1991. Human endothelial cells are activated by IFN-gamma to inhibit Toxoplasma gondii replication. Inhibition is due to a different mechanism from that existing in mouse macrophages and human fibroblasts. J. Immunol. 147: 2019-2023. 